volume may be about the true volume of the non-cohering molecules, as stated above.

II. From these conclusions it is evident that the theory of compressible atoms affords a satisfactory explanation for the inadequacy of the equation of van der Waals and the equation of corresponding states derived from it. The latter equation would be expected to hold better than the former, because the same kinds of deviations often exist in different gases, and the method of comparison may eliminate these.

CaMBridge, Mass.

[Contributron from the Chemical laboratories of New Hampshire College.]

\title{
THE DOUBLE SULFATES OF SAMARIUM WITH SODIUM AND AMMONIUM.
}

\author{
By D. B. KeYYS AND C. JAMES. \\ Received February 16, 1913.
}

The solubility curves of the sulfates of samarium, gadolinium, yttrium and ytterbium in sodium sulfate seem to be of special interest. Samarium can be looked upon as being the first element whose double sulfate with sodium sulfate is distributed between the insoluble double sulfates and the more soluble ones. The solubility curve of gadolinium sulfate in sodium sulfate should show the reasons why some writers claim that gadolinium may be separated from the yttrium earths by this process, while others state that it can be separated from the cerium earths by this very method. Yttrium, possessing the average'properties of the yttrium rare earths, as far as these compounds are concerned, shows the best concentrations under which the most complete separation can be obtained. ${ }^{1}$ The curve given by ytterbium sulfate under these conditions would indicate, very nearly, the extreme solubilities. It would also show whether a concentrated solution of sodium sulfate would leave the members of the rare earth series, possessing the highest atomic weights, in solution accompanied by smaller amounts of the other yttrium earths.

This present communication deals with the compounds formed by samarium sulfate with the sulfates of sodium and ammonium.

The pure samarium sulfate was prepared in the following manner: Samarium oxalate was ignited and the oxide dissolved in hydrochloric acid. To the cool solution there was added a little more sulfuric acid than was required to unite with the samarium present, after which the mixture was poured into a large excess of alcohol. The precipitated sulfate was filtered off, washed with alcohol and rendered anhydrous by heating. The anhydrous sulfate was dissolved in water, filtered, and the filtrate evaporated upon the steam bath. The purified salt was then dried and very finely powdered.

'This has been worked out by C. James and H. C. Holden. This Journal, 35, 559. 
Samarium Sodium Sulfate.-In order to study the system samarium sulfate, sodium sulfate and water, about twenty bottles were made up of varying concentrations. One bottle was used to determine the solubility of samarium sulfate.

After rotating for a long time in a thermostat at $25^{\circ}$, the analysis of the liquid phase was commenced. The procedure was as follows: two samples were removed by means of a pipet, weighed and diluted to about roo cc. each. The first was acidified with hydrochloric acid and the samarium precipitated as samarium sebacate by the addition of a solution of ammonium sebacate. The precipitate was filtered off, washed and ignited to the oxide $\mathrm{Sa}_{2} \mathrm{O}_{3}$. The percentage of $\mathrm{Sa}_{2}\left(\mathrm{SO}_{4}\right)_{3}$ was then determined from the weight of oxide.

The second diluted sample was acidified with hydrochloric acid, brought to boiling, and the $\mathrm{SO}_{3}$ precipitated by the addition of barium chloride solution. The precipitate was filtered, washed, ignited and weighed. This gave the total amount of $\mathrm{SO}_{3}$. By deducting the amount of $\mathrm{SO}_{3}$ required for the samarium sulfate, the quantity that was combined with the sodium was then obtained.

The results of the analyses were as follows:

\begin{tabular}{|c|c|c|c|c|c|}
\hline Serial No. & $\begin{array}{l}\mathrm{Na}_{2} \mathrm{SO}_{4} \text { per } 100 \\
\text { parts of } \mathrm{H}_{2} \mathrm{O} \text {. }\end{array}$ & $\begin{array}{c}\mathrm{Sa}_{2}\left(\mathrm{SO}_{4}\right)_{3} \text { per } \\
100 \text { parts of } \mathrm{H}_{2} \mathrm{O} .\end{array}$ & Serial No. & $\begin{array}{l}\mathrm{Na}_{2} \mathrm{SO} \text { per } 100 \\
\text { parts of } \mathrm{H}_{2} \mathrm{O} \text {. }\end{array}$ & $\begin{array}{c}\mathrm{Sa}_{2}\left(\mathrm{SO}_{4}\right)_{3} \text { per } \\
100 \text { parts of } \mathrm{H}_{2} \mathrm{O} .\end{array}$ \\
\hline $1-4 \ldots \ldots$ & 0.1 & 2.0 & I $3 \ldots$ & $\mathrm{I} 4.7 \mathrm{I}$ & 0.010 \\
\hline $5 \ldots \ldots$ & 0.5 & O. II I & $1+\ldots$ & $14 \cdot 4 \pi$ & 0.009 \\
\hline $6 \ldots \ldots$ & I. 9 & 0.0 .3 & $1_{5} \ldots \ldots$ & 20.02 & 0.012 \\
\hline $7 \ldots \ldots$ & 6.44 & 0.016 & I $6 \ldots$ & 23.42 & 0.012 \\
\hline $8 \ldots \ldots$ & 7.00 & 0.008 & $\mathrm{r} 7 \ldots$ & 23.68 & 0.018 \\
\hline $9 \ldots$. & 9.02 & 0.016 & $18 \ldots$ & $25 \cdot 9.3$ & o.OIS \\
\hline $10 \ldots . .$. & $10.5 \mathrm{I}$ & 0.012 & $19 \ldots$ & $27 \cdot 40$ & O.OI \\
\hline$I I \ldots \ldots \ldots$ & I I, $4^{8}$ & 0.012 & $20 \ldots$ & $\ldots$ & 2.05 \\
\hline I $2 \ldots \ldots \ldots$ & . $\quad 13.58$ & 0.010 & & & \\
\hline
\end{tabular}

These results, which are plotted in Fig. I, appear to indicate that there is only one double salt formed by the union of samarium sulfate with sodium sulfate.

The double compound was. prepared by mixing a saturated solution of samarium sulfate with a saturated solution of sodium sulfate, and allowing the resulting solution to stand for about two days. The precipitate was filtered off, dried, ground and washed with water and alcohol.

This salt was analyzed in the following way: a $0.5 \mathrm{~g}$. sample was fused in a platinum crucible with sodium potassium carbonate. The whole was dissolved in water, leaving $\mathrm{Sa}_{2} \mathrm{O}_{3}$. This was filtered, washed and ignited, and dissolved in very dilute hydrochloric acid. The chloride solution was then brought to a boil and precipitated by ammonium sebacate. The liquid was allowed to set in an oven at $90^{\circ}$ for one hour, and then filtered. The precipitate was washed and ignited to the oxide. The 
$\mathrm{SO}_{4}$ was obtained by precipitating with barium chloride in the acidified filtrate from the $\mathrm{Sa}_{2} \mathrm{O}_{3}$.

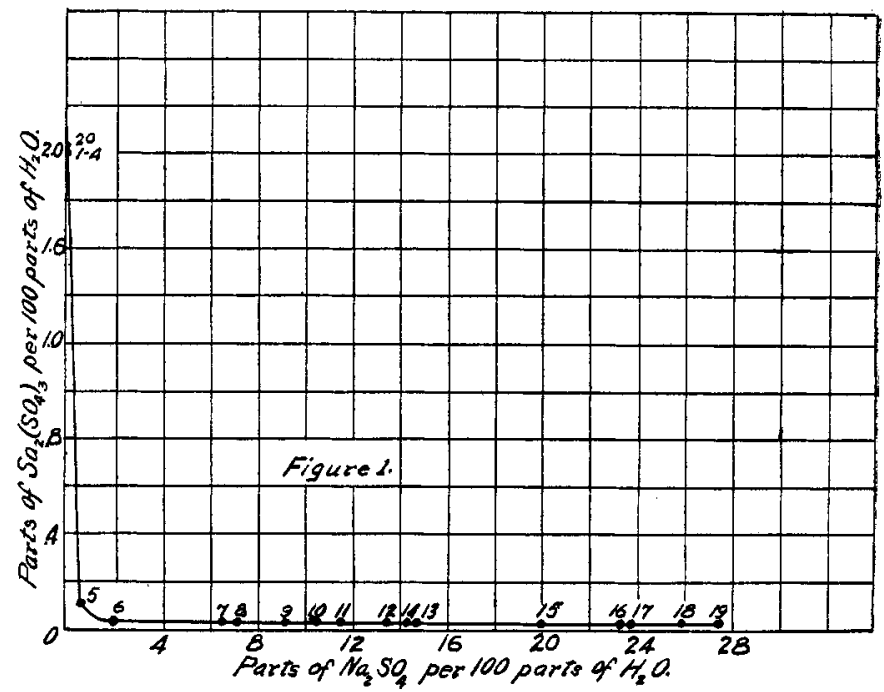

Two solutions of samarium sulfate were used to prepare the double compound. One contained about 10\% sodium sulfate, while the other contained about $20 \%$.

The results of the analysis together with the ratio of molecular weights are given below.

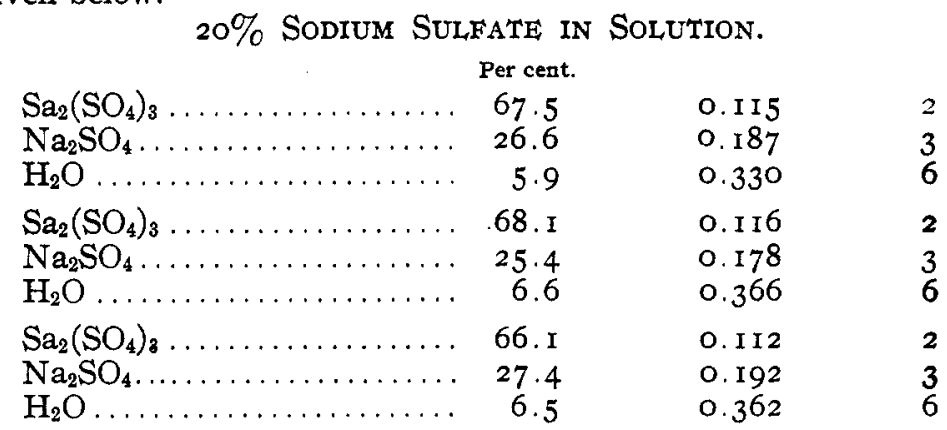

Analysis of the compound formed from the 10\% solution of sodium sulfate showed approximately the ratio $2-3-6$, similarly to the $20 \%$ solution.

It can be seen that the results vary considerably. This is probably due to difficulties in the method of analysis. However at no time could the results, regardless of error, come to such values as to give the ratios. I-I-2, which have been accepted up to the present time. ${ }^{1}$

1 Bull. soc. chim., 43, I62. 
DOUBLE SULFATES OF SAMARIUM WITH SODIUM AND AMMONIUM. 637

It appears, therefore, to the authors that the composition of the compound is $2 \mathrm{Sa}_{2}\left(\mathrm{SO}_{4}\right)_{3} \cdot 3 \mathrm{Na}_{2} \mathrm{SO}_{4} \cdot 6 \mathrm{H}_{2} \mathrm{O}$.

Samarium Ammonium Sulfate.-Eighteen bottles of varying concentrations were made up and placed in a thermostat at $25^{\circ}$. After rotating for five months the solutions were found to be in equilibrium and the analysis was commenced. The procedure for the liquid phase was identical with that in the former system, with the exception that the ammonia was driven off by boiling with a slight excess of sodium hydroxide before acidifying and precipitating with barium chloride to determine the $\mathrm{SO}_{3}$. The results of the analyses are given below.

\begin{tabular}{|c|c|c|c|c|c|}
\hline Serial No. & $\begin{array}{c}\mathrm{Sa}_{2}\left(\mathrm{SO}_{4}\right)_{3} \\
\text { per } 100 \\
\text { parts of } \mathrm{H}_{2} \mathrm{O} .\end{array}$ & $\begin{array}{c}\left(\mathrm{NH}_{4}\right)_{2} \mathrm{SO}_{4} \\
\text { per } 100 \\
\text { parts of } \mathrm{H}_{2} \mathrm{O} .\end{array}$ & Serial No. & $\begin{array}{r}\mathrm{Sa}_{2}(\mathrm{SO} \\
\mathrm{per} 10 \\
\text { parts of } 1\end{array}$ & $\begin{array}{l}\left(\mathrm{NH}_{4}\right)_{2} \mathrm{SO}_{4} \\
\text { per } 100 \text { parts } \\
\text { of } \mathrm{H}_{8} \mathrm{O} \text {. }\end{array}$ \\
\hline I..... & $2 . I$ & 0.3 & 10 $\ldots \ldots \ldots \ldots$ & . $\quad 0.8$ & 12.2 \\
\hline $2 \ldots \ldots$ & 2.0 & 0.8 & $11 \ldots \ldots \ldots$ & . . 0.8 & 12.3 \\
\hline $3 \ldots$ & 2.8 & I. I & $12 \ldots \ldots$ & . $\quad 0.9$ & 32.5 \\
\hline $4 \ldots \ldots \ldots \ldots$ & I. 5 & I. 9 & $13 \ldots \ldots \ldots$ & . . 1.0 & 46.3 \\
\hline $5 \ldots \ldots \ldots$ & I. 2 & 2.7 & $14 \ldots \ldots \ldots$ & . . $\quad 0.9$ & 40.3 \\
\hline $6 .$. & 0.8 & 7.4 & $15 \ldots \ldots \ldots$ & I. 3 & $77 \cdot 5$ \\
\hline 7 . & 0.8 & 9.5 & $16, \ldots \ldots \ldots$ & . $\quad 0.2$ & 77.2 \\
\hline $8 \ldots \ldots \ldots$ & 0.8 & 8.7 & $17 \ldots \ldots \ldots$ & . . 0.3 & $77 \cdot 3$ \\
\hline $9 \ldots \ldots \ldots \ldots$ & 0.8 & 18.8 & $18 \ldots \ldots \ldots$ & . . 0.6 & 76.8 \\
\hline
\end{tabular}

Bottles 2, 3, 9, II I I4 and I5 were checked and found correct.

The curve shown in Fig. 2 was drawn from the above data. Along the first part of the curve (from I to 3 ) we have the solubility of samarium

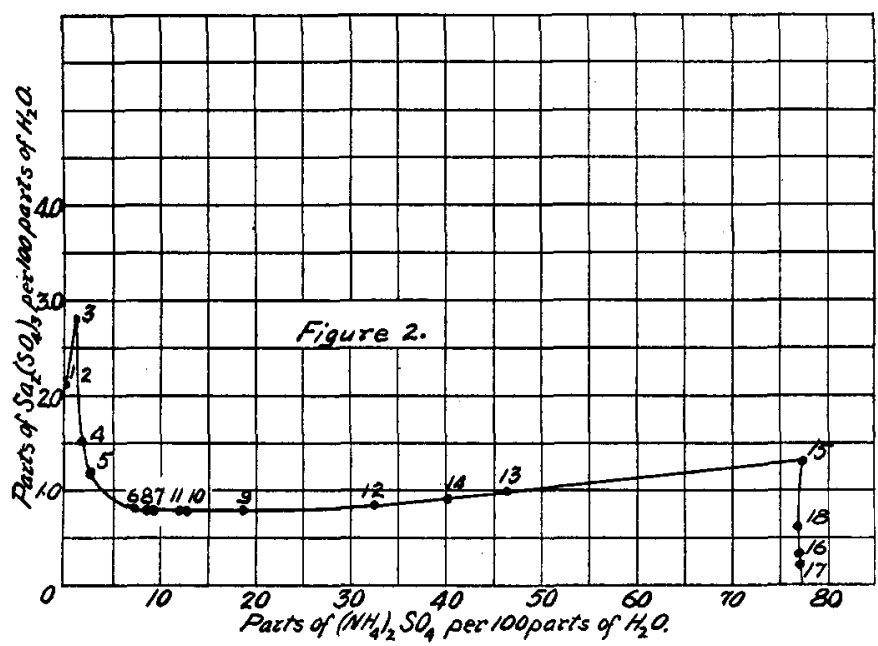

sulfate. From 3 to $1_{5}$, the curve represents the solubility of the double compound, while from ${ }_{15}$ on, the solubility of ammonium sulfate is represented.

The solid phase was removed from some of the bottles, and carefully analyzed, with the following results: 


\begin{tabular}{|c|c|c|c|}
\hline No. & $\% \mathrm{Sa}_{2}\left(\mathrm{SO}_{4}\right)_{3}$. & $\%_{0}\left(\mathrm{NH}_{4}\right)_{2} \mathrm{SO}_{4}$ & $\% \mathrm{H}_{2} \mathrm{O}$. \\
\hline 5 . & . 61.7 & 13.0 & $25 \cdot 3$ \\
\hline & . $\quad 55.9$ & 15.2 & 28.9 \\
\hline & . $\quad 57.0$ & 13.7 & 29.3 \\
\hline 13. & . $\quad 55 . \mathrm{I}$ & 17.9 & 27.8 \\
\hline
\end{tabular}

From these results and from the corresponding liquid phase the triangular plot shown in Fig. 3 was made.

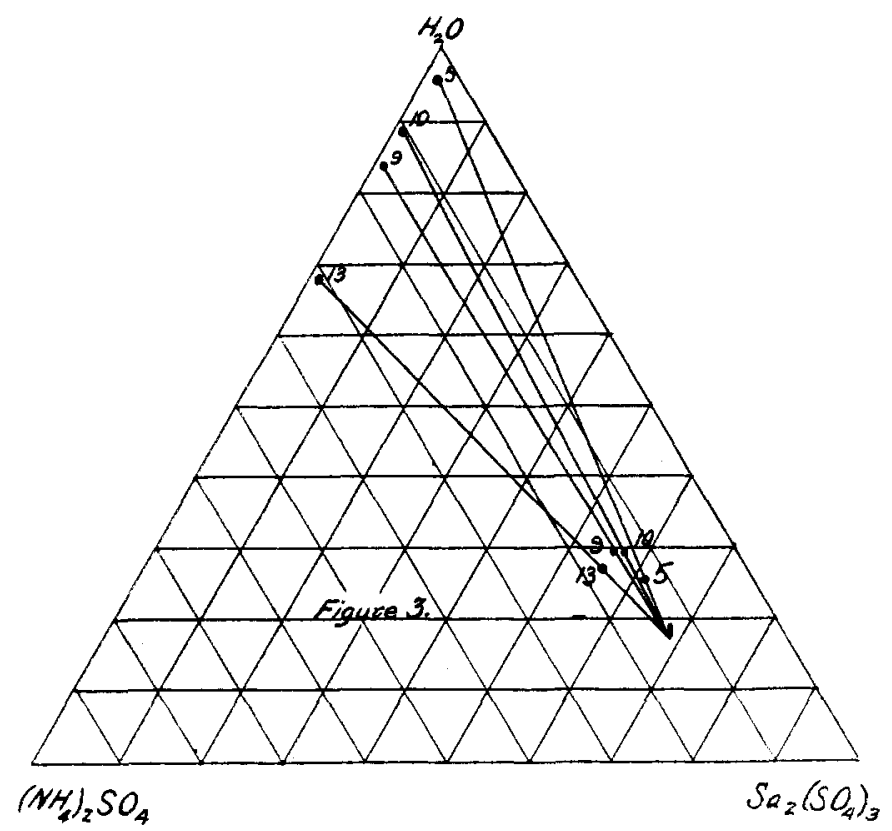

It will be observed that the lines intersect at a common point corresponding with the formula $\mathrm{Sa}_{2}\left(\mathrm{SO}_{4}\right)_{3} \cdot\left(\mathrm{NH}_{4}\right)_{2} \mathrm{SO}_{4} \cdot 7 \mathrm{H}_{2} \mathrm{O}$.

Some of the pure compound was prepared by washing away the ammonium sulfate from some of the solid phase from bottle 5. Analysis showed that the composition agreed well with that indicated above. This formula is similar to the one given by Cleve, with the exception of the amount of water of crystallization. ${ }^{1}$

DUREAM, N. H.

[Contribution from the Chemical Laboratories of New' hampshire College.] THE SEPARATION OF YTTRIUM FROM THE YTTRIUM EARTHS.

\section{PART I.}

By H. C. Holden and C. James.

Received February 16, 1914.

Although the rare earth oxides obtained from minerals such as gadolinite, fergusonite, euxinite, samarskite and xenotine carry a large percentage of

${ }^{1}$ Bull. soc. chim., 43, 162. 